\section{Effects of Arc Stage of Electrical Discharge on Ignition of Inflammable Gas}

THERE is at present no generally accepted criterion of spark ignition. A widely held view is that energy delivered to the gas is the main criterion. Kravchenko ${ }^{1}$ has advanced the thesis that the energy in the are stage of the discharge is the sole criterion, and that other discharge conditions, such as glow, are incapable of giving rise to ignition. During the course of investigation on inductive break-spark ignitions, a number of records of current and voltage across the discharge were taken with high-speed oscilloscopes. A current of $185 \mathrm{~m}$.amp. was interrupted in a $95-\mathrm{mH}$. inductance series circuit, and the resulting discharge was made to take place in an explosive mixture of $8 \cdot 3$ per cent methane in air. Oscillographic studies of similar discharges in air have been made by Nethercot and Rehfisch ${ }^{2}$, with lower time-base sweep-speeds and non-simultaneous recording of current and voltage.

The patterns of arc, glow and multiple spark were found to be similar in the explosive mixture and in air. In general, most records showed arc stages lasting up to some $30 \mu \mathrm{sec}$. However, a number of records were obtained where a recognizable are stage was limited to a few microseconds as in Fig. 1, or was non-existent as in Fig. 2, and these gave normal ignitions in an $8 \cdot 3$ per cent mixture of methane in air. To resolve detail in the multiple breakdowns shown in the records, simultaneous voltage and current recordings were taken at a time-base speed of $0.1 \mu \mathrm{sec} . / \mathrm{cm}$. Fig. 3 shows such a voltage record and Fig. 4 a corresponding current record, taken under conditions identical with those in Figs. 1 and 2. It is seen that nowhere is there a characteristic arc step; the wave carrying a superimposed high-frequency oscillation is likely to be due to the local oscillatory circuit at the contacts. A detailed examination of a number of records has shown that ares are established at the two levels of 96 and $144 \mathrm{~V}$. and glows at $384 \mathrm{~V}$. It is therefore clear that ignition is not dependent on the are stage of the discharge.

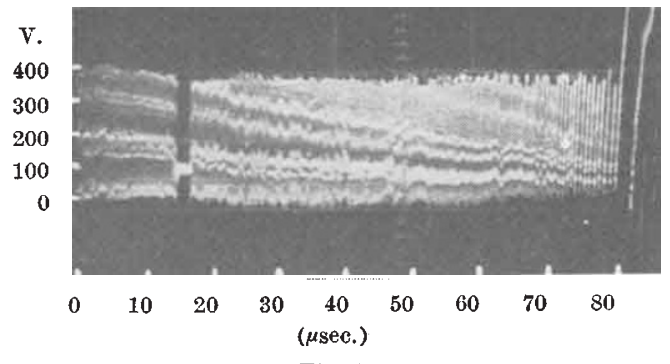

Fig. 1

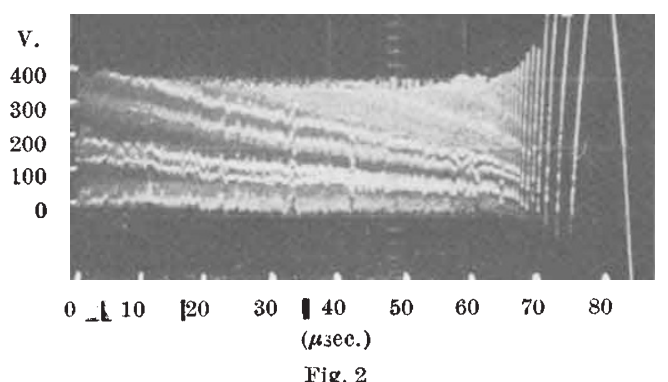

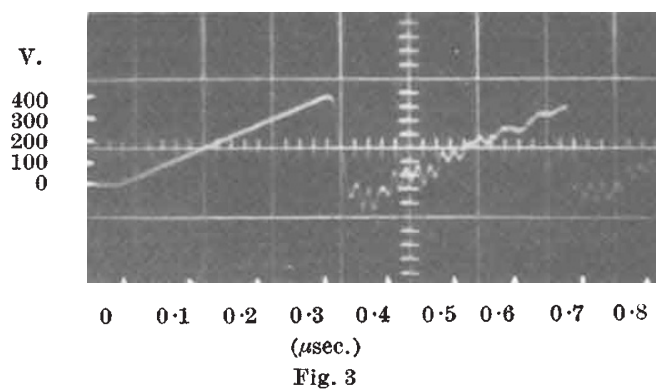

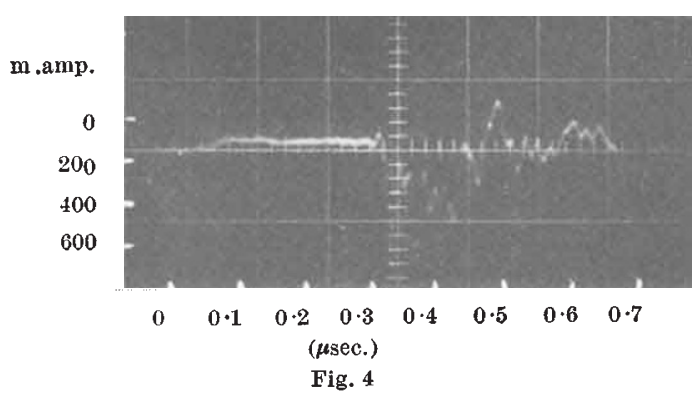

This communication is published by permission of Dr. W. Idris Jones, director-general of research in the Scientific Department of the National Coal Board, and covers work forming part of the programme of research of the Mining Research Establishment. The views expressed are my own and not necessarily those of the Board.

Mining Research Establishment,

I. BERZ Worton Hall,

Isleworth, Middlesex.

${ }^{1}$ Kravchenko, V. S., Trudy Institute Gornovo Dela, 203 (1954).

" Nethercot, W., and Rehfisch, T. J., E.R.A. Report G/T 217 (1948).

WE agree entirely with $\mathrm{Mr}$. Berz that an are discharge is not essential for the ignition of inflammable gas, but we cannot agree with his statement that the multiple breakdowns shown in his records have none of the characteristics of an are discharge. We suggest that they are transient ares of very short duration in which the current is relatively constant as is the voltage, although its value is appreciably greater than that in a sustained discharge.

Multiple discharges, which often occur when inductive circuits are broken, are due to the capacitance associated with the circuit inductance and the opening contacts. At current break this capacitance is charged up at a rate which is dependent primarily on the values of the capacitance and the inductance. For short times the rate of rise of voltage is linear and the charging current is constant, as shown in the oscillograms of Figs. 3 and 4 of Mr. Berz's communication. When the voltage reaches the breakdown voltage of the gap, in this case about $400 \mathrm{~V}$., the capacitive energy $\frac{1}{2} C V^{2}$ is rapidly discharged through the gap by the establishment of a short transient arc. The capacitance is then recharged through the inductance and the cycle is repeated until the breakdown voltage of the gap rises with increasing gap-width to a value which is greater than the peak value of the open-circuit oseillation.

From the results provided by Mr. Berz's oscillograms it is possible to deduce that the capacitanco 